\title{
16
}

\section{REPRESENTATIONAL AND \\ ANIMATIC CORPOREALITY}

\section{Refiguring bodies and digitally mediated cities}

\author{
Gillian Rose
}

\section{Introduction: mediating posthuman embodiment}

This chapter approaches the contemporary refiguration of urban space by exploring how embodiment is being reconfigured in digitally mediated cities. For Kember and Zylinska $(2012,40)$, mediation is 'a multiagential force that incorporates humans and machines, technologies and users, in an ongoing process of becomingwith'. Hence,

mediation becomes a key trope for understanding and articulating our being in, and becoming with, the technological world, our emergence and ways of interacting with it, as well as the acts and processes of temporarily stabilizing the world into media, agents, relations, and networks.

(Kember and Zylinska 2012, xv)

This chapter focuses specifically on how the flows of data that now saturate so many cities are mediating (post)human embodiment, and in particular how a specific form of spatiality is part of that mediating stabilisation of corporeality - a spatiality that also refigures urban space.

The chapter assumes that corporeality is a process and that different embodiments are co-produced with different kinds of technologies. Visual technologies are especially important in this process, particularly in cities that are full of people looking at images of other people, on digital screens, in that city or somewhere else. Data that become images of various kinds are a significant part of the immense streams of digital data flowing through and beyond cities, including images of cities and their inhabitants (McQuire 2016). Created and processed, distributed and redistributed, some will materialise as figurative images like photorealistic advertisements, news videos or selfies. Some will be converted into types of data visualisations: a symbol 
on a map, a node in a network, a category in a graph. These many image types are seen variously in their turn, studied, glanced at, swiped through (Rose and Willis 2019; Krajina 2014). Made somewhere and uploaded, travelling somewhere else, being reconfigured, analysed, or multiplied, and then being downloaded, perhaps to the same device, perhaps to many others, in the same place or elsewhere: these are the distributed circuits of many forms of visual media now (Browne 2015; Casetti 2015). And at the interface between a digital image and its viewers, particular kinds of bodies coagulate.

In urban studies, most of the attention given to digital mediation has focused on the 'smart city' and its flows of big digital data (key references include Greenfield 2013; Hollands 2016; Hollands 2008; Kitchin 2014; Marvin, Luque-Ayala, and McFarlane 2016; Karvonen, Cugurullo, and Caprotti 2018). The term 'smart' refers to the use of digital data to improve urban governance. For example, city authorities and commercial providers suggest that smart policies and technologies can enhance environmental sustainability by enabling more efficient use of resources, especially energy and water; or that traffic flow or air pollution can be improved by using real-time environmental data; or that economic growth can be increased by innovating new products and markets based on digital data. Attention has also been given to the range of commercial platforms that collate and integrate urban data, such as Airbnb, Uber, and Mobike (Barns 2020). As various feminist critics have pointed out, however, most of this work focuses on the agency of digital infrastructure and the political economy of its data extraction (Leszczynski 2019; Rose 2017). Inspired by decades of intersectional feminist work, this chapter instead asks how to see bodies in this context.

This is an important question to ask since much of the data circulating through urban spaces are related to bodies. Corporations and city authorities produce, analyse, and visualise data about populations, citizens, commuters, taxpayers, users, residents, and consumers, among others (Rose et al. 2020). Residents and tourists take and look at selfies, influencer videos, video chats, and GIFs on WhatsApp, Instagram and TikTok. That is, much of the data that circulate through and about cities materialise as images on some kind of screen, showing and being seen by specific bodies. The chapter approaches this visuality as a form of technosociality. Ways of seeing are co-constituted by the affordances of technologies, the social practices in which those technologies are embedded, their discursive framings and affective dispositions (see Gordon 2010; Otter 2008; Wilson 2014). The phrase 'ways of seeing' was coined by John Berger (1972). The chapter follows his use of the term to refer not only to what is seen but also to the body doing a particular kind of visualising. 'Though obviously one who sees, an observer is more importantly one who sees with a prescribed set of possibilities, one who is embedded in a system of conventions and limitations' (Crary 1990, 6). Berger was also attentive to (some of) the ways in which the relation between seer and seen is always riddled with power. If visual images 'body forth' corporeality (Copier and Steinbock 2018, 924), these are of specific kinds, in particular relations. 
Many digital images mimic visual genres with long histories, which shape their making and viewing. Maps generated by geographical information systems may use the same data and be seen in the same way as earlier hand-drawn maps of census data, for example; three-dimensional digital models of urban morphology may be used in the same way as the physical architectural models. But the chapter suggests that these ways of seeing and constituting bodies are being joined by other ways of seeing other forms of embodiment, which are caught up with the specific dynamics of data circulation. Specifically, the chapter suggests that animatic embodiment is part of the digital refiguration of urban bodies and space.

To make this argument, it draws on Deborah Levitt's (2018) account of animation. Animation brings things to life. For Levitt $(2018,1)$, animation is 'the dominant medium of our time', moving us from 'questions about ontology, category, and being to ones of appearance, metamorphosis, and affect' (Levitt 2018, 2). Animation is both a medium and a contemporary cultural condition, according to Levitt. Its logic is not based on correspondence with a real; instead, animations envision metamorphosis, erasure, and resurrection rather than ontological presence. Schematically, the chapter argues that the spatial organisation of bodies in cities is also shifting between representational and animatic forms - and so, too, are city spaces.

\section{Animation, softimages, and urban bodies}

For Levitt, 'new forms of life and vitality emerge at the spectator-screen intersection as this transforms over time' (Levitt 2018, 3). While not directly determined by technological changes in the spectator-screen intersection, animatic life is enabled by some of the specific dynamics of digital images. It is important, therefore, to say a little more about how digital visual imagery is different from previous image forms. Hoelzl and Marie's $(2015,7)$ discussion of what they term the 'softimage' is useful here:

As a program, the image, while still appearing as a geometrical projection on our screens, is inextricably mixed up with the data (physical and digital) and the continuous processing of data. What was supposed to be a solid representation of a solid world based on the sound principle of geometric projection (our operational mode for centuries), a hard image as it were, is revealed to be something totally different, ubiquitous, infinitely adaptable and adaptive and intrinsically merged with software: a softimage.

A defining element of that merger is the software that allows digital images to be networked images (Munster and MacKenzie 2019; Rubinstein and Sluis 2008). The shift from analogue to digital popular photography was enabled by not only digital cameras but also increasingly seamless connections between cameras, other viewing devices such as computers, and then phones and social media platforms. Social media is saturated with images, of course, and design professionals create 
elaborate computer-generated images via a global division of labour (Chung 2018; Rose, Degen, and Melhuish 2014). Images appear on multiple screens, in different forms, at different sites. They are shared and favourited, liked or deleted, copied and posted, circulated and recirculated. There are nonhuman agencies at play here, too. Many visual data are processed algorithmically; indeed, Steyerl $(2017,47)$ suggests that 'contemporary perception is machinic to a large degree. The spectrum of human vision covers only a tiny part of it'. The speed of image production, processing, and circulation is enacting a shift to 'something more akin to live transmission' (Rubinstein and Sluis 2008, 22). The speed and scale of image production and analysis suggests not so much a network as a vast

stratified constellation of technical memory matter, composed of resources that shape political and cultural imaginaries ... with depth, height, scale, extensiveness and duration . . . moving in different directions. . . . Its forms may change and its content migrate, accruing or shedding textures in the process.

(Withers 2015, 17)

Softimages, then, are networked, processed, live, and distributed (cf. Rose 2016). So, how are bodies visually mediated by softimages? The chapter will now sketch two visual regimes: the representational and animatic. Representational and animatic ways of seeing are not completely distinct, nor do they map neatly onto different technologies (as Levitt [2018] notes). Technologies, practices, discourses, and affects all contribute to each visual regime. Many digital images mimic the appearance of non-digital images and are observed in ways that those have long been observed, as representations of particular forms of urban life: closed circuit-television footage taken with digital cameras, for example, can be seen in the same way as video-taped CCTV. Animatic refigurations of urban environments and inhabitants, however, invite a different way of seeing — emergent, distributed, transformational — whether they are hand-drawn cartoons of urban superheroes or real-time maps of Twitter sentiment.

\section{Seeing cities representationally}

With those caveats in mind, the chapter now indicates how bodies and cities continue to be visualised through representational ways of seeing. Drawing on Barad, Kember and Zylinska $(2012,31)$ describe representationalism as the conviction that what is represented exists independently of all practices of representation. Representational ways of seeing assume that there is a real that images - no matter how selective and distorted-re-present to the viewer. In terms of visuality, cinema and photography have both been understood as media that are themselves representational but are also parts of a wider representational visual culture, which Levitt calls the 'cinematic regime' composed of 'light, the machine, and an analytic eye' (Levitt 2018, 12). In Levitt's account, as in that of many others, this is not the only 
visuality enacted by cinema. However, the dominant representational cinematic regime sees bodies in particular ways. What we see when we see bodies cinematically are 'autonomous, massy entities' (Levitt 2018, 12) that refer to a pro-filmic real. Twentieth-century traditions of urban documentary photography, for example, are usually cinematic.

For Levitt, then, the representational cinematic regime entails the seeing of massy bodies by an analytic eye. In terms of thinking about bodies in urban space, seeing bodies as fleshy entities to be analysed is part of the 'productive, biopolitical dimensions of cinema in the discourse of reflection, representation, and reality' (Levitt 2018, 11). That is, the representational cinematic regime is aligned with Foucauldian biopower (Levitt 2018, 28). This is a crucial step in understanding representational regimes of urban visuality. Representational urban visuality sees bodies as masses: as epidermal volumes with surfaces that can be analysed and categorised.

In biopolitical regimes, ways of seeing analyse bodies through discursive codes and, in so doing, enact a range of social categories such as sex, gender, and race (along with distinguishing between bodies that are human and not [Butler 2007]). Feminist, critical race, and crip scholarship have been particularly attentive to this process. From hooks (1992) and Bordo (1993) to Weheliye (2014), Browne (2015), and Benjamin (2019), the ways in which bodies' surfaces are marked with, and interpreted through, signs of social difference have been described. And this analytical, biopolitical way of seeing continues in the digitally mediated city. 'Visual technologies and racial taxonomies fashion each other' (Benjamin 2019, 99). Corporeal bodies are rendered (as the) real surface on which particular social categories are visible. Facial 'recognition' software can identify the gender, sex, race, and even sexuality of bodies, we are told (though their failures are also regularly reported [Leszczynski 2019]). The notion of 'recognition' here exemplifies the representational regime in which a reality is there to be recognised; and also obscures the process by which algorithms are trained to produce that 'recognition' by human operators (Benjamin 2019). We might also consider the ways in which big urban data are converted into conventional demographic or geospatial categories and then into dashboard displays (Ruppert 2012).

Urban spaces are also visualised representationally in the cinematic regime. Visual technologies of many kinds are put to work to identify truths about the city. Images - photographs, maps, diagrams, graphs - are understood to represent some aspect of an urban reality. From creating and mapping data to photographing housing defined as slums, visual techniques for seeing cities and their inhabitants became part of understanding and governing urban spaces.

Understanding the digital mediation of bodies and cities as representational produces a particular form of critique. Much criticism of the algorithmic production of urban code/space (Kitchin and Dodge 2011) is based on the representational assertion of a 'radical incommensurability between embodied and represented life' (Agostinho 2018, 143). Assuming that incommensurability exists between a real and its representation, this way of seeing is challenged because it 'renders some 
things more visible than others, yielding new parameters of visibility that determine who or what dis/appears' (Agostinho 2018, 132). Thus, planners' and developers' digital images of new urban developments are criticised for their inaccuracy: too clean, too sunny, too wealthy. In this regime, the who and the what exist before they are brought into, or excluded from, visibility.

It is this assumption of a pre-existing real that animatic ways of seeing abandon. Levitt's (2018) account of the representational cinematic regime and the animatic apparatus is careful not to assume a recent and complete transition from a filmbased regime to a software-based apparatus. She is also careful not describe specific visual technologies as either representational or animatory. As she notes, films can be animated and animations can be representational. She does suggest, however, that a new technological and discursive dispositif is emerging in which 'it doesn't matter so much what life is, as rather you can do with it' (Levitt 2018, 20). She suggests that this is a wider cultural shift, and, like Clough (2018), she references the life sciences where bodies are increasingly understood less as corporeal masses and more and more as information that-ever since gene-splicing, DNA mapping, and transgendered bodies became possible — can be transformed and recombined.

\section{Animatic embodiment}

The mediation of bodies into data happens in a great number of everyday urban contexts, as noted in the introduction to this chapter. And while some of that mediation may take representational forms, animation also occurs, more and more often. Deleuze (1992) famously argued that the biopolitical was being displaced by what he termed 'societies of control'. In societies of control, the social is constituted through constantly mediated data and there is no sense of an incommensurability between that data and a real. (Incommensurability remains but is better thought of as glitches within and between different data flows, as Leszczynski [2019] argues.)

If animation is a cultural condition, then one of its central dynamics is the circulation and recombination of data: 'big data sorting that is designed to collate seemingly unrelated sets with the intention of producing novel relations' (Clough 2018, 107). Emergent patterns within and between data replace correspondence between image and reality and between sign and category. As Rouvray (2013) points out, this algorithmic logic 'spares [humans] the burden and responsibility of transcribing, interpreting and evaluating events of world. It spares them the meaning-making processes of transcription or representation'. Animatic embodiment in a smart city is configured by such emergent, algorithmic constellations of data. The boundary between the corporeal body and the network no longer holds. 'Embodiment cannot be contained within the organic skin' when traces of digital data now so fundamentally compose what has to be called the posthuman (Clough 2018, xxxii). Bodies are turned into data and the algorithmic analysis of big data produces new corporeal entities (Rose et al. 2020).

Gabrys's (2014) discussion of smart citizenship is exemplary here. Gabrys explores the notion of smart citizenship assumed by a smart city design proposal and 
suggests that the production of digital data produces smart citizens as 'ambividuals': citizen-subjects whose emergence is contingent on events, articulated through the technologies and practices of computational urbanism. Citizenship, she suggests, can thus become less an individualised subjectivity and more a digitally mediated distribution, configuring 'ambient and malleable urban operators that are expressions of computer environments' (Gabrys 2014, 42-43).

But what does this animated embodiment in a smart city look like? If the bodies in digitally mediated cities are not all configured as the 'body-asorganism', the body that we see pictured, the massy body bounded by skin, if some forms of embodiment do not look like that anymore, then how do we see them?

Levitt's (2018) response is to look at a range of visual animations differently. She looks and reads a range of films and books not as representations but as animations. In animations, says Levitt, things are only erased, mutated, or resurrected; things are not categorised but transformed. Her methodology is therefore to read animations not for their correspondences, references, and presences, but rather for their transformative generation of novel sensations. Animation must be seen as an enactment; it exemplifies, not signifies; it must be looked at less for what and more for how. She turns her gaze to dolls, automata, cyborgs, and robots, and other urban inhabitants that have long featured in films as not-quite-human. These are figures, she says, that continue to look human enough for viewers to relate to them but that are also different enough to suggest other forms of lively animation. They retain 'just enough resemblance so that its potentials - if not the extent of its "dimensions, depths, and distances"-become graspable' (Levitt 2018, 51). This potential is the animatory vitality of recombinant invention and other forms of emergent embodiment.

Here we might turn to semi-autonomous technologies such as food delivery robots, trundling alongside other pedestrians, or driverless cars; we might consider the 'data doubles' that shadow corporeal bodies in city streets (Cheney-Lippold 2017). But we might also turn to the viewer in animatic ways of seeing. Rather than the cinematic regime's positioning of the analytical spectator as separate from the screen, animations tend to merge and exchange image space and body space (Levitt 2018, 83). The screen is now an interface. 'A user is not consolidated in identity but rather . . . consist [s] of roving populations of action in the network' (Halpern 2015, 240). No longer a single point of view framed by perspectival techniques, the spectator becomes a constantly mobile point of view, decentred, zooming and hovering through an environment that seems to have no frame. Elsaesser $(2013,240)$ describes this unanchored viewing, tracking seamlessly through spaces from the nano to the planetary, as 'the default value of digital vision' (and points to its non-digital precedents in a range of efforts to create convincing three-dimensional films).

This suggests that looking for animatory embodiments means being particularly attentive to erasure, mutation, re-emergence, mobility, and this is a vocabulary that is as much spatial as visual. 


\section{Refiguring city spaces as animatory}

If animatory bodies are organised as emergent, combinatory patterns of data, then so too are the spaces of digitally mediated cities. Geographers have been particularly attentive to the various dynamics through which city spaces are digitally refigured (Rose 2017; 2018; Wilmott 2016; Wilson 2014). Here, the plethora of digital visualisations that now bring urban spaces into visibility are particularly relevant (Halpern 2015). Cities now are insistently visualised through multiple interfaces, in different formats, genres, and media. There is no single frame, no nest of scales, no coherent territory. Different images merge and blend, and the same image reappears in different contexts. Rather like Steinbock's (2019) trans account of cinema, this is a way of seeing cities through cuts and layers, disjunctures and recombinations, mutations and excrescences. References to a real become references to multiple reals, which become a seamless dissolution of one real into another, which in turn becomes more visual flow, exemplified in videos evoking the smart city that seamlessly mutate between multiple types of visualisations of city spaces (Rose 2018). Cities are thus also constantly transformed in the 'mixed-space effect' of animation (Levitt 2018, 68).

An example, paradoxically, is the smart city control centre. As the site for visualising many kinds of data regarding a city, a smart control centre without doubt works in part on a representational logic: what truth is this data representing, and how therefore should the city be managed? However, as Luque-Ayala and Marvin (2016; Marvin and Luque-Ayala 2017) point out in their accounts of Rio de Janeiro's smart operations centre, the centre is also a site that generates multiple spatialities through which Rio materialises differently. It enacts an infrastructure through which all sorts of things move- people, electricity, rainfall, traffic-but which may also fail at any moment. The operations centre produces a network of logistical circulation but is also a nodal site for maintenance and incident control. Through the operations centre, 'the city is reconfigured as a space of agility, efficiency, modularity, flexibility and configurability' (Marvin and Luque-Ayala 2017, 92), and these spaces of the digitally mediated urban operating system may not align. The city as bricolage morphs between these configurations as the data from all kinds of urban sensors flicker across its screens.

\section{Re-refiguring digitally mediated cities and bodies}

So, if we think about the digitally mediated city and ask — where are the bodies?this chapter has suggested that there are several ways to answer the question. Drawing on Levitt's (2018) work, the chapter has sketched a regime of representation and what it makes visible, and a regime of animation and how it makes things live. The chapter has discussed how bodies in the digitally mediated city can be thought of representationally in terms of features distributed across epidermal surfaces, which represent certain pre-existing social categories and can be analysed. Animatic bodies, on the other hand, are seen and sensed as constantly emergent, mobile, fluid, 
and mutating. These two configurations are constitutive of not only how embodiments are made visible but also different regimes of seeing. Moreover, they constitute different organisations of urban space. Representational and animatic bodies are constituted through different kinds of spatial organisation, and so too are the cities they inhabit. Urban representational regimes proffer a city about which some truths can be known. Animatic cities, on the other hand, are fluid and emergent.

The question of power in this visual culture remains, as always. Representational and animatic regimes of urban embodiment have different accounts of power. In representational regimes, power consists of the ability to analyse, identify, and label bodies and spaces; to misrepresent; to exclude and render invisible. The power of animatic regimes also rests in the power to analyse and define, but also to extract, transfigure, morph, and assimilate corporealities and cities. Each requires different actions, engagements, resistances, and ethics. Urban scholars often seek resistance to exclusion. But animation demands a different critique. If the animatic apparatus

reorders the self as data . . then it is important to continue opening out the question of the self and its constituent, relational others in order to see what kinds of relations are facilitated and prohibited in the process and what consequences various enactments of relationality will have, for 'us' and 'the world' at large.

(Kember and Zylinska 2012, 112)

The challenge, then, is to calibrate potentials for other transformations and potentials (Clough 2018), and other recombinations (Rose 2017), in urban data circulations.

\section{References}

Agostinho, Daniela. 2018. "Chroma Key Dreams: Algorithmic Visibility, Fleshy Images and Scenes of Recognition." Philosophy of Photography 9 (2): 131-155.

Barns, Sarah. 2020. Platform Urbanism: Negotiating Platform Ecosystems in Connected Cities. Basingstoke: Palgrave Macmillan.

Benjamin, Ruha. 2019. Race After Technology: Abolitionist Tools for the New Jim Code. Cambridge: Polity Press.

Berger, John. 1972. Ways of Seeing. London: BBC with Penguin.

Bordo, Susan. 1993. Unbearable Weight: Feminism, Western Culture, and The Body. Berkeley: University of California Press.

Browne, Simone. 2015. Dark Matters: On the Surveillance of Blackness. London: Duke University Press.

Butler, Judith. 2007. "Torture and the Ethics of Photography." Environment and Planning D: Society and Space 25 (6): 951-966.

Casetti, Francesco. 2015. The Lumière Galaxy: Seven Key Words for the Cinema to Come. New York: Columbia University Press.

Cheney-Lippold, John. 2017. We Are Data: Algorithms and the Making of Our Digital Selves. New York: New York University Press. 
Chung, Hye Jean. 2018. Media Heterotopias: Digital Effects and Material Labor in Global Production. London: Duke University Press.

Clough, Patricia Ticineto. 2018. The User Unconscious: Affect, Media and Measure. London: University of Minnesota Press.

Copier, Laura, and Eliza Steinbock. 2018. “On Not Really Being There: Trans` Presence/ Absence in Dallas Buyers Club." Feminist Media Studies 18 (5): 923-941.

Crary, Jonathan. 1990. Techniques of the Observer: On Vision and Modernity in the Nineteenth Century. Cambridge, MA: MIT Press.

Deleuze, Gilles. 1992. "Postscript on the Societies of Control." October 59: 3-7.

Elsaesser, Thomas. 2013. "The 'Return' of 3-D: On Some of the Logics and Genealogies of the Image in the Twenty-First Century." Critical Inquiry 39 (2): 217-246.

Gabrys, Jennifer. 2014. "Programming Environments: Environmentality and Citizen Sensing in the Smart City." Environment and Planning D: Society and Space 32 (1): 30-48.

Gordon, Eric. 2010. The Urban Spectator: American Concept Cities from Kodak to Google, 1st ed. Hanover, NH: Dartmouth College Press.

Greenfield, Adam. 2013. Against the Smart City. London: Do Projects.

Halpern, Orit. 2015. Beautiful Data: A History of Vision and Reason since 1945. Durham NC: Duke University Press.

Hoelzl, Ingrid, and Rémi Marie. 2015. Softimage: Towards a New Theory of the Digital Image. Bristol: Intellect Books.

Hollands, Robert G. 2008. "Will the Real Smart City Please Stand Up?” City 12 (3): 303-320.

Hollands, Robert G. 2016. "Beyond the Corporate Smart City? Glimpses of Other Possibilities of Smartness." In Smart Urbanism: Utopian Vision or False Dawn, edited by Simon Marvin, Andrés Luque-Ayala, and Colin McFarlane, 169-185. London: Routledge.

hooks, bell. 1992. Black Looks: Race and Representation. Boston: South End Press.

Karvonen, Andrew, Federico Cugurullo, and Federico Caprotti, eds. 2018. Inside Smart Cities: Place, Politics and Urban Innovation, 1st ed. London: Routledge.

Kember, Sarah, and Joanna Zylinska. 2012. Life After New Media: Mediation as a Vital Process. Cambridge, MA: MIT Press.

Kitchin, Rob. 2014. "The Real-Time City? Big Data and Smart Urbanism." GeoJournal 79 (1): 1-14.

Kitchin, Rob, and Martin Dodge. 2011. Code/Space: Software and Everyday Life. Cambridge, MA: MIT Press.

Krajina, Zlatan. 2014. Negotiating the Mediated City: Everyday Encounters with Public Screens. London: Routledge.

Leszczynski, Agnieszka. 2019. "Glitchy Vignettes of Platform Urbanism.” Environment and Planning D: Society and Space 38 (2): 189-208. doi: 10.1177/0263775819878721.

Levitt, Deborah. 2018. The Animatic Apparatus: Animation, Vitality, and the Futures of the Image. Winchester: Zero Books.

Luque-Ayala, Andrés, and Simon Marvin. 2016. "The Maintenance of Urban Circulation: An Operational Logic of Infrastructural Control." Environment and Planning D: Society and Space 34 (2): 191-208.

Marvin, Simon, and Andrés Luque-Ayala. 2017. "Urban Operating Systems: Diagramming the City." International Journal of Urban and Regional Research 41 (1): 84-103.

Marvin, Simon, Andrés Luque-Ayala, and Colin McFarlane, eds. 2016. Smart Urbanism: Utopian Vision or False Dawn? Abingdon: Routledge.

McQuire, Scott. 2016. Geomedia: Networked Cities and the Future of Public Space. Cambridge: Polity Press. 
Munster, Anna, and Adrian MacKenzie. 2019. "Platform Seeing: Image Ensembles and Their Invisualities." Theory, Culture \& Society 36 (5): 3-22. doi: 10.1177/0263276419847508.

Otter, Chris. 2008. The Victorian Eye: A Political History of Light and Vision in Britain, 18001910. London: University of Chicago Press.

Rose, Gillian. 2016. "Rethinking the Geographies of Cultural 'Objects' through Digital Technologies: Interface, Network and Friction.” Progress in Human Geography 40 (3): 334-351.

Rose, Gillian. 2017. "Posthuman Agency in the Digitally Mediated City: Exteriorization, Individuation, Reinvention." Annals of the American Association of Geographers 107 (4): 779-793.

Rose, Gillian. 2018. "Look Inside ${ }^{\mathrm{TM}}$ : Visualising the Smart City.” In An Introduction to Geomedia: Spaces and Mobilities in Mediatized Worlds, edited by Karin Fast, André Jansson, Johan Lindell, Linda Ryan Bengtsson, and Mekonnen Tesfahuney, 97-113. London: Routledge.

Rose, Gillian, Monica Degen, and Clare Melhuish. 2014. "Networks, Interfaces, and Computer-Generated Images: Learning from Digital Visualisations of Urban Redevelopment Projects." Environment and Planning D: Society and Space 32 (3): 386-403.

Rose, Gillian, Parvati Raghuram, Sophie Watson, and Edward Wigley. 2020. "Platform Urbanism, Smartphone Applications and Valuing Data in a Smart City." Transactions of the Institute of British Geographers 1-14. doi: 10.1111/tran.12400.

Rose, Gillian, and Alistair Willis. 2019. "Seeing the Smart City on Twitter: Colour and the Affective Territories of Becoming Smart." Environment and Planning D: Society and Space 37 (3): 411-427.

Rouvroy, Antoinette. 2013. "The End(s) of Critique: Data Behaviourism versus Due Process." In Privacy, Due Process and the Computational Turn: The Philosophy of Law Meets the Philosophy of Technology, edited by Mireille Hildebrandt and Katja de Vries, 143-167. Abingdon: Routledge.

Rubinstein, Daniel, and Katrina Sluis. 2008. "A Life More Photographic: Mapping the Networked Image.” Photographies 1 (1): 9-28.

Ruppert, Evelyn. 2012. "Category." In Inventive Methods: The Happening of the Social, edited by Celia Lury and Nina Wakeford, 36-47. Abingdon: Routledge.

Steinbock, Eliza. 2019. Shimmering Images: Trans Cinema, Embodiment, and the Aesthetics of Change. London: Duke University Press.

Steyerl, Hito. 2017. Duty Free Art: Art in the Age of Planetary Civil War. London: Verso.

Weheliye, Alexander G. 2014. Habeas Viscus: Racializing Assemblages, Biopolitics, and Black Feminist Theories of the Human. Durham NC: Duke University Press.

Wilmott, Clancy. 2016. "In-between Mobile Maps and Media: Movement." Television \& New Media 18 (4): 320-335.

Wilson, Matthew W. 2014. "Continuous Connectivity, Handheld Computers, and Mobile Spatial Knowledge." Environment and Planning D: Society and Space 32 (3): 535-555.

Withers, Deborah. 2015. Feminism, Digital Culture and the Politics of Transmission. London: Rowman \& Littlefield International. 